\title{
STATISTICAL RETROSPECTIVE STUDY OF SUICIDES IN THE PLEVEN DISTRICT - BULGARIA FOR A 10-YEAR PERIOD
}

\author{
D. Dekov $^{1 *}$, I. Veleva ${ }^{2}$, I. Stoilova ${ }^{3}$ \\ ${ }^{1}$ Department of General and Forensic Medicine and Deontology, Faculty of Public Health, \\ Medical University - Pleven, Bulgaria \\ ${ }^{2}$ Department of Psychiatry and Medical Psychology, Faculty of Public Health, \\ Medical University - Pleven, Bulgaria \\ ${ }^{3}$ Department of Hygiene, Medical Ecology, Occupational Diseases and Disaster Medicine, \\ Faculty of Public Health, Medical University - Pleven, Bulgaria
}

\begin{abstract}
Suicides are an important and current social and medical problem of the modern society.

According to the National statistics for the period 2000-2010 in Bulgaria there have been 11646 suicides or death due to intentional self-harm. The objective of this study is to research the dynamics and structure of suicides in the county of Pleven for the past ten years, distributions based on gender, age, place of residence, chronobiology, cause of death, as well as other details.

Subject of retrospective analysis is forensic medicine reports from the archives of the Department of Forensic Medicine at the Medical University-Pleven.

366 cases were investigated over a period of 2008 to 2017 years. The results show that men are 230 $(62.8 \%)$ and women $136(37.2 \%)$. The same ratio applies between residents in town and village. The highest is the number of suicides in the age interval between 61 and 70 years. According to the causes of death, the highest number is due to hanging -176 cases or $48 \%$, followed by jumping from high buildings and poisoning. In $14 \%$ of cases presence of alcohol in the blood was found. Most suicides occur in March, followed by June and July, and according to days of the week - on Tuesdays and Fridays. The blood types of the suitcidants in the district of Pleven were compared to those in the district of Plovdiv, as well as the distribution for the whole Republic of Bulgaria. Finally, there is a comparison of similarities and differences with the results of other studies.
\end{abstract}

Key words: suicide, forensic medicine report, statistics.

\section{INTRODUCTION}

Suicides are an important and current medical and social problem of modern society. Globally, there is an increasing tendency in number and this highlights the issue of their prevention, the establishment and development of a prevention strategy. In the last 50 years, the suicide rate worldwide has increased by $60 \%$, according to a World Health Organization report. According to him, every year about 1 million people worldwide commit suicide, or approximately one case of a person who deliberately takes their life every 40 seconds on the planet (1). Only clear cases of suicide fall into official statistics, so the

\footnotetext{
*Correspondence to: Dekov D. P

(drdekov@abv.bg), Faculty of Public Health, Medical University - Pleven, 1, Kliment Ohridski str, 5800 Pleven, Republic of Bulgaria
}

number of real suicides is significantly higher than those figures - it is estimated that more than 3,000,000 people take their lives annually in the world (2).

According to the background of the worsening health-demographic characteristics in Bulgaria, the premature loss of human potential is a serious problem. According to National Statistics data, 11646 Bulgarians committed suicide or died of deliberate self-harm during the period 2000-2010. Suicide in men accounts to 8626 cases and in women - 3020. Most suicides in Bulgaria were committed in 2000 1383, and the least in 2010 - 859. However, our country makes some progress in the prevention of suicide during the last a decade, with the number of suicides declining by over $30 \%$ over the period 2000 to 2012 (3). 
Regardless of the established and implemented suicide prevention program in Bulgaria, according to experts, the collection of information about suicide attempts is incomplete and of low quality. For this reason, all studies providing additional information are important for updating the strategy and optimizing a prevention program.

\section{PURPOSE AND OBJECTIVES}

To investigate the dynamics and structure of suicides in the Pleven region for the last 10 years, the distribution of cases by gender, age, residence, chronology and causes of death of the event, as well as other signs. To summarize the data, to compare with the results of other authors and the data of the National Statistics. To indicate similarities and differences. To make the appropriate conclusions to help develop the prevention program in the region and reduce significantly their number.

\section{MATERIAL AND METHODS}

DEKOV D., et al.

In total, 366 cases of suicides from the archives of the Department of Forensic Medicine at the University Hospital in Pleven for the period 2008 - 2017 have been investigated and proven by the relevant authorities (police and prosecutors). The analysis was performed on the basis of forensic examinations for carcass study and autopsy journals. The data was digitalized and processed with the Microsoft Excel software. The methods used are archival-documentary and statistical.

\section{RESULTS AND DISCUSSION}

The 366 suicide cases investigated accounted for $19 \%$ of all forensic medical examinations for carcass testing and $26.7 \%$ of all cases of violent death in the region for the same period. The absolute number of suicides ranges from 30 in 2007 to 46 cases in 2016, an average of 36.6 per year.

Table 1. Suicide cases breakdown by year

\begin{tabular}{|l|l|l|l|l|l|l|l|l|l|}
\hline 2008 & 2009 & 2010 & 2011 & 2012 & 2013 & 2014 & 2015 & 2016 & 2017 \\
\hline 31 & 31 & 44 & 38 & 38 & 35 & 33 & 40 & 46 & 30 \\
\hline
\end{tabular}

In the year of the last census in our country2011, the population in the Pleven region was 269,752 . In calculating the suicidal index for the area (suicide rate per 100,000 people), in the same year we receive 14 , which is slightly higher than the average for the country in 2012, which is 12 per 100,000 people (Table 1).
The gender breakdown is as follows: men 230 cases or $62.8 \%$ and women 136 cases or $37.2 \%$. The male / female ratio is 1.69: 1 . In most countries around the world, the number of suicides for men exceeds that of women, except India and Pakistan $(4,5)$. Surveys of some of our authors for different regions gave an average ratio of male and female suicides 2.8: 1 and 2.3: $1(6,7)$

Table 2. Suicide cases breakdown by age group and gender

\begin{tabular}{|l|l|l|l|l|l|l|l|l|}
\hline $\begin{array}{l}\text { Up to } 18 \\
\text { years }\end{array}$ & $\begin{array}{l}18-30 \\
\text { years }\end{array}$ & $\begin{array}{l}31-40 \\
\text { years }\end{array}$ & $\begin{array}{l}41-50 \\
\text { years }\end{array}$ & $\begin{array}{l}51-60 \\
\text { years }\end{array}$ & $\begin{array}{l}61-70 \\
\text { years }\end{array}$ & $\begin{array}{l}71-80 \\
\text { years }\end{array}$ & $\begin{array}{l}\text { Over } 80 \\
\text { years }\end{array}$ & Total \\
\hline 2 & 7 & 29 & 46 & 46 & 67 & 61 & 61 & 366 \\
\hline
\end{tabular}

The increase in the total number of suicides increases with age and reaches its peak in the age group between 61-70 years, followed by a slight decline (Table 2).

The ratio of urban to rural population is 230 $(62.8 \%)$ to $136(37.2 \%)$.

The rural population in the Pleven region covers only one-third of the total, and the relative share of suicides among the rural population is slightly higher. For a higher suicide index among the rural population, especially among elderly people over 60 , there are reports from other national authors as well (6-10).

The analysis of our material on the causes of death is the following:

Hanging - 176 cases or $48 \%$

192
Jumping from buildings- 75 cases or $20 \%$

Poisoning - 45 cases or $12 \%$

Firearm injuries - 32 cases or $9 \%$

Drowning - 17 cases or 5\%

Train-related injuries - 11 cases or $3 \%$

Electrocution - 7 cases or $2 \%$

Self-ignition - 3 cases or $1 \%$

The results show that the most preferred method is hanging (48\%) of all cases (men cover $70 \%$, women $30 \%$ ). The second most "preferred" method, which covers $20 \%$, is jumping from buildings ( $73 \%$ of them are men, the remaining $27 \%$ are women). Third (12\%) are poisonings, where two thirds are women. Fourth (9\%) is the use of firearms used only by men. Fifth place is drowning, which covers 5\% and is more preferred by women. The least popular are suicides such as train-related 
injuries, electrocution and self-ignition, which cover a total of 21 cases.

Baltov's(6) studies in the Plovdiv region point hangings at first place, secondly jumping from high and third use of firearms. Studies of Lisaev et al (7) on 1396 cases from the Pleven and Lovech regions for the period 1979-1995 rank the most used methods of hanging, poisoning, jumping from high. The hanging remains the most prevalent way of suicide all over the world. The highest levels are reported in Eastern European countries such as Lithuania, Poland, Romania (1). Only in Australia and New Zealand the percentage among men is below 50(1).

In 51 of the cases (or 14\%) in the biological fluids of the autopsy, an alcohol content of more than 0.5 has been found, which suggests that the person has consumed alcohol and was influenced by that before the death. Of these, only 5 are women, the other 46 are men. The role of alcohol is to increase aggressiveness, mental stress, and drive suicidal thoughts (1113). In different countries alcohol consumption is different, which also reflects the published data. Most authors report that the majority of alcohol-use cases were in males $(6,7,11-13)$ although among the younger people who tried to commit suicide, the consumption of alcohol in women is more common. It turns out that alcohol contributes to the deaths of more than a third of suicide individuals. The use of alcohol along with suicide attempts is associated with repeated attempts to commit suicide, and very often with future suicide (2).

In 49 cases (or 13\%), death occurred in a hospital after failed treatment. In three cases, death occurred in the ambulance during transportation to the hospital, and in the rest, the body was found in place.

For some mental disorders, the risk of suicide is greater at certain times or episodes in the course of the disease. For example, in the course of a severe depressive disorder, suicidal
DEKOV D., et al. tendency often occurs before a diagnosis is made or treatment is started. In patients with severe depressive disorder with bipolar depression or schizophrenia, it is also found that suicidal tendency is most likely to occur early in the disease (2). In our research only in 48 cases $(13 \%)$, there was evidence of severe mental illness (epicrisis, Work Capability Assessment Commission (TELK) protocols, or testimony from relatives) were found at the site. In 14 of these cases, prior suicide attempts were reported. As these data is not directly related to the conclusion of forensic expertise, they are not actively sought and not all are mentioned in the archival documents examined. We believe that the number of mentally ill among the suicides is significantly higher, but the lack of a register of the mentally ill in Bulgaria does not allow us to consult and to clarify how many these cases are in reality.

In $16(7 \%)$ of cases, the suicides left a predeath letter and 16 other relatives reported suicidal thoughts.

In 289 cases of suicide, the blood group was examined. In the remaining 77 cases, it was not determined due to haemolysis of the blood. Studies on the relationship between the suicide type of blood type and the number of suicides in Bulgaria have not been conducted except in Baltov (6) in Plovdiv. Data on this issue in foreign literature is diverse.

In $16(7 \%)$ of cases, the suicides left a suicide note and 16 other relatives reported suicidal thoughts.

In 289 cases of suicide, the blood group was examined. In the remaining 77 cases, it was not determined due to haemolysis of the blood. Studies on the relationship between the suicide type of blood type and the number of suicides in Bulgaria have not been conducted except in Baltov (6) in Plovdiv. Data on this issue in foreign literature is diverse.

Table 3. Blood type of the suicides in Pleven, compared to the suicides in Plovdiv and the distribution of the blood types in the Republic of Bulgaria

\begin{tabular}{|l|l|l|l|l|}
\hline Blood type & A & B & 0 & AB \\
\hline $\begin{array}{l}\text { Among the population in the } \\
\text { Republic of Bulgaria }\end{array}$ & $44,2 \%$ & $15,4 \%$ & $32,2 \%$ & $8,2 \%$ \\
\hline Among suicides in Pleven region & $44,7 \%$ & $18,3 \%$ & $32,5 \%$ & $4,5 \%$ \\
\hline Among suicides in Plovdiv region & $45,1 \%$ & $17,5 \%$ & $31,0 \%$ & $6,4 \%$ \\
\hline
\end{tabular}

The results show that in the Pleven region individuals with blood type $\mathrm{AB}$ perform fewer and those with blood type "B" more suicides compared to the distribution of blood types among the population in Bulgaria (Table 3).
For blood types $\mathrm{A}$ and 0 the figures do not show high statistical significance.

According to the months of the year, the peak of suicide is March - 42, followed by June and July by 39 . This differs from the publications 
of other authors who point a peak in May and June or June and July (6-10). The lowest levels are in December -16 and January-17. These
DEKOV D., et al.

results coincide or are similar to those published by the same authors.

Table 4. Distribution of suicide cases according to the days of the week

\begin{tabular}{|r|r|r|r|r|r|r|r|}
\hline Monday & Tuesday & Wednesday & Thursday & Friday & Saturday & Sunday & Total \\
\hline 55 & 58 & 50 & 42 & 58 & 45 & 48 & 356 \\
\hline
\end{tabular}

In 10 cases, the exact date of death was not clearly established, so the total number of cases was 356 . The highest number of suicides are on Tuesday and Friday with 58 cases each, or $16.3 \%$, and the smallest on Thursday - 42 or $11.8 \%$. These results are opposite to those of Milev et al (9) who report that the most suicide attempts are taking place on Thursday with the results of G. Petkov et al (14) who find that this happens in the middle of the week on Wednesday afternoon. Baltov's forensic study on 944 cases showed the highest number of suicides on Monday with 155 or $16.42 \%$ and the lowest on Thursday 113 cases or $11.97 \%$ (Table 4) (6).

\section{CONCLUSION}

Our survey covers a small territory and population of the Republic of Bulgaria (area $4337 \mathrm{~km} 2$ and population 248138 people as of December 31, 2016), which does not allow cardinal summaries to be made. However, the results of this regional study should be taken into account when setting up measures to reduce suicide. The forensic statistics of suicides in Pleven show the following:

1.The number of suicides committed accounts for more than a quarter of all cases of violent death.

2. The suicide index among the rural population is higher than in the urban population.

3. Hanging is the most preferred method for both men and women.

4.Suicides among men are more than among women.

5. The lowest is the number of suicides in December and January.

These characteristics do not differ significantly from the data of the National Statistical Institute and the studies of other authors for other regions as well as from most of the general trends in the world over the last decades.

As distinctions and characteristics of the region, we can identify the following:

1. Most suicides were committed in March.

2. Most suicides were registered on Tuesday and Friday.

3. Patients with blood type $A B$ perform fewer suicides and blood group $\mathrm{B}$ more than the distribution of the same blood types among the population in Bulgaria.

\section{REFERENCES}

1. W H O - Suicide Statistics, Geneve 2010; www.who.int/en/.

2. Stoimenova, M, Suicide: a way out or a solution?, DITA -M, Sofia, p.132-144 (in Bulgarian), 2014.

3. www.nsi.bg/bg/content/766/.

4. Hasyanova S., Naidenova V , Structure of death rates in males in productive age in Udmartia in 2003-2004, in Problems of medical expertise, №4, $\mathrm{p}=22-24$ (in Russian), 2005.

5. Khan M, Reza $\mathrm{H}$. The pattern of suicide in Pakistan. Crisis; 20: 67-70, 2000.

6. Baltov $M$ Suicides in Plovdiv region: the forensic medicine perspective. $\mathrm{PhD}$ thesis abstract Plovdiv (in Bulgarian), 2013.

7. Lisaev P, Dorovski P, Dekov D, Deyanov S, Totev P. Analysis of suicides for a period of 17 years in a population of 500 thousand, Socail medicine, No2, p. 25-28 (in Bulgarian), 1997.

8. Gaidarova R. Suicides, Pleven, p. 31 (in Bulgarian), 1998.

9. Milev V, Monov A, Mihov D, Simeonova R. Suicide attempts and geomagnetic storms, Neurology, Psychiatry and neurosurgery, Sofia, XXXI, 3, p. 197-203. (in Bulgarian).

10.Tzoneva-Pencheva L. Suicide attempts and toxic substances abuse, Hygiene and health protection, №2-3, p. 53-55 (in Bulgarian), 2001.

11.Battistini A., Gentile G., Plazzo E., Zoja R. Train - related suicides in Milan, Italy: analysis of cases 1993-2008. Med. Sci. Law., Jul, 49 (3): 185-90, 2009.

12.Copeland AR, Suicide by jumping from buildings. Am. J. Forensic Med. Pathol., Dec. 10 (4): 295-8, 1989.

13. Sher L. Alcoholism and suicidal behavior, Acta Psychiatrica Scandinavica, 113, 1322, 2006.

14.Petkov G, Shishkov A, Komsiiska D et al. Causes, mechanisms and suicide prevention in children and adolescents, Bulgarian medicine, Vol IV, 5-6, p 35-38. (in Bulgarian), 1996. 